\title{
The validation of a self-report measure and physical activity of Australian Aboriginal and Torres Strait Islander and non-Indigenous rural children
}

\author{
Josephine D. Gwynn \\ Faculty of Health, University of Newcastle, New South Wales
}

\author{
Louise L. Hardy \\ Physical Activity, Nutrition and Obesity Research Group, University of Sydney, \\ New South Wales
}

John H. Wiggers, Wayne T. Smith, Catherine A. D'Este
Faculty of Health, University of Newcastle, New South Wales

Nicole Turner

Durri Aboriginal Corporation Medical Service, Kempsey, New South Wales

\section{Janine Cochrane}

Biripi Aboriginal Medical Service, Taree, New South Wales

\author{
Daniel J. Barker, John R. Attia \\ Faculty of Health, University of Newcastle, New South Wales
}

\begin{abstract}
Purpose: To validate a self-report measure of physical activity for both Australian Aboriginal and Torres Strait Islander and non-Indigenous rural children, and to describe their physical activity participation. Methods: In this cross-sectional study, 84 Aboriginal and Torres Strait Islander and 146 non-Indigenous children aged 10-12 years old completed the Many Rivers Physical Activity Recall Questionnaire (MRPARQ), a modified version of the Adolescent Physical
\end{abstract} Activity Recall Questionnaire (APARQ). A sub-group ( $n=86$ ) wore an accelerometer for seven consecutive days in order to validate the instrument.

Results: Pearson and Intra Class Correlation coefficients between the survey and acceleromtery for weekdays only are 0.31 and 0.16 , respectively, for Aboriginal and Torres Strait Islander children, and 0.38 and 0.31 , respectively, for non-Indigenous children, and demonstrate a modest $(p<0.05)$ correlation.

Self-reported MVPA for Aboriginal and Torres Strait Islander children is between 162 and 172 minutes/day, and is 125 minutes by accelerometer; for non-Indigenous children MVPA is between 123 and 149 minutes (survey) and 107 minutes (accelerometer).

Conclusion: Australian Aboriginal and Torres Strait Islander children's self-report of physical activity is at least as valid as non-Indigenous children, given culturally appropriate support; they tend to be more active than non-Indigenous children. Implications: The MRPARQ can be administered with Aboriginal and Torres Strait Islander and non-Indigenous children.

Key words: validity; accelerometer; selfreport; Australian Aboriginal and Torres Strait Islander children; physical activity.

Aust NZ J Public Health. 2010; 34:S57-65 doi: 10.1111/j.1753-6405.2010.00555.x 
evaluation of health programs with this population, who bear a high health burden, but also because of concerns about this method's cultural appropriateness. ${ }^{4,15}$ The only self-report measure of physical activity validated among Australia's Aboriginal and Torres Strait Islander children is the previous day (24 hr) physical activity recall measure (PDPAR-24).${ }^{14}$ A significant limitation of the PDPAR-24 is the need for multiple administrations to obtain a reliable estimate of a child's habitual physical activity level, which in population studies, is a major drawback. There is, therefore, a need to find alternative instrument valid for use with Aboriginal and Torres Strait Islander children.

The survey used in this study is a modified version of the Adolescent Physical Activity Recall Questionnaire (APARQ), ${ }^{16}$ an instrument currently in use in NSW as part of a tool to monitor trends in physical activity and nutrition among youth in Years 6 , 8 and 10. The APARQ records information about the frequency and duration of young people's usual weekly physical activity participation in organised and non-organised physical activities, during summer and winter school terms, has acceptable to good reliability, and weak to moderate validity against the Multistage Fitness Test a test of cardio-respiratory fitness (Spearman correlation coefficients $0.14-0.39$ ). In this study the APARQ was modified to assist the recall of rural Aboriginal and Torres Strait Islander and non-Indigenous children aged 10 to 12 years, named the Many Rivers Physical Activity Recall Survey (MRPARQ) and validated using accelerometry as the criterion. ${ }^{16}$

This study was part of the Many Rivers Diabetes Prevention Project and the two aims were first, to examine the validity of the MRPARQ among Aboriginal and Torres Strait Islander and non-Indigenous children rural children aged 10 to 12 years, and second, to describe the physical activity of these children by using both self-report and accelerometer as complementary measures. We report the levels, variables associated with, and type of physical activity, as well as the percentage of children with $\geq 60$ mins'day of MVPA for both groups.

\section{Methods}

\section{Design}

A cross-sectional study of school children aged 10-12 years (Grades 5 and 6) was conducted in late 2005 and early 2006. Eleven priority-funded NSW Department of Education and Training primary schools in three regional areas on the north coast were invited to participate. These schools were selected because they had high enrolments of Aboriginal and Torres Strait Islander children. Informed consent by children and their carers was a requirement for participation. The study was approved by the Hunter Area Health Service, the Mid North Coast Health Service, the University of Newcastle, the NSW Department of Education and Training and the Aboriginal Health and Medical Research Council of NSW.

\section{Participants}

In two regions, all children in Grades 5 and 6 at the selected schools received a letter of invitation to participate in the study, distributed by the class teacher, with only Aboriginal and Torres Strait Islander children receiving follow-up invitations to participate. In the third region only Aboriginal and Torres Strait Islander children were invited to assist with the recruitment of Aboriginal and Torres Strait Islander children to the study. Indigenous status was determined from school enrolment data, which is ascertained from parental responses to a standard question on the school enrolment form regarding the Indigenous status of their child.

\section{Measures}

Researchers recorded demographic information on each child, including their sex, date of birth and Indigenous status. Height and weight were measured, body mass index calculated $\left(\mathrm{kg} / \mathrm{m}^{2}\right)$ and students were categorised as not overweight/obese, overweight or obese according to the international definitions. ${ }^{17}$

\section{Self-report physical activity}

The MRPARQ is modified from the APARQ which is described in detail elsewhere. ${ }^{16}$ Briefly, children were asked to think about a normal week in summer and winter school terms, and to report separately, participation in all organised and non-organised physical activities. Organised activities were defined as those that usually involve competition, training and adult supervision (e.g. dance, swimming, team sports). Non-organised activities were defined as those that did not involve competition or training and that were unsupervised by adults (e.g. skateboarding, walking, ball games, chores). For each activity reported, students stated the frequency and duration of their participation on weekdays and/or weekends, in summer and/or in winter. The MRPARQ was developed in consultation with the Aboriginal Health Workers (AHWs) on the project; includes only large font text essential to child's completion of the survey; and uses headings for key parts of the week including 'after school' and 'weekends'. The poster used in the administration of the MRPARQ included pictures of local activities performed by our participants and was based on information gathered in focus groups conducted previously in another phase of this program of research with children of the same age and from the same schools as those who participated in this study. The survey was administered to children seated in small groups with one or two members of the research team, which always included an AHW.

\section{Objective measurement of physical activity}

Physical activity was objectively measured continuously for seven consecutive days using an MTI Actigraph accelerometer $(7,146)$ (Actigraph, Pensacola, FL). The Actigraph accelerometer is a small, lightweight instrument that is recognised as a valid and reliable instrument for assessing physical activity in children and adolescents, and has been used extensively in studies of physical activity in young people..$^{2,18-20}$ Field staff fitted the children with the accelerometer. The children were instructed to wear the accelerometer over the right hip, except when in water, sleeping or participating in vigorous or contact sports (such as rugby or netball), when they were advised to seek guidance from a supervising adult regarding suitability to wear, or remove it themselves if they judged this appropriate. The children were also provided with written information on wearing the accelerometer and contact numbers for assistance. Two research staff (including an AHW) visited the children each day, except on weekends, to provide support. 


\section{Aboriginal and Torres Strait Islander children}

Culturally appropriate support was provided for Aboriginal and Torres Strait Islander children. Central to this was the high-profile role of the AHWs who lived in the participating communities and were employed on the project to facilitate recruitment of Aboriginal and Torres Strait Islander children, and support their completion of all study procedures. AHWs liaised with schools; co-presented the introductory sessions; supported completion of the survey; took height and weight measurements; supported the children's wearing of the accelerometer by visiting and encouraging each child each weekday; and provided support to family and community as needed.

\section{Statistical analysis}

\section{Self-reported physical activity}

For each activity, the frequency of participation was multiplied by the duration per session to give total time spent in that activity each week. Each physical activity was assigned a MET ( $\mathrm{kcals} / \mathrm{kg} / \mathrm{min}$ ) value $^{21}$ and time (mins/day) spent in light ( $<3$ METs), moderate ( $\geq 3$ to 5.9 METs) vigorous ( $\geq 6 \mathrm{METs}$ ), and moderate-to-vigorous (MVPA $\geq 3$ METS) physical activity calculated separately for week and weekend days.

\section{Accelerometer-based physical activity}

Seven days of 24-hour minute-by-minute activity counts were downloaded from the accelerometers to Excel spreadsheets, then imported to SAS (version 9.1). For the analyses, accelerometer data collected between 8.00 am and $6.30 \mathrm{pm}$ on weekdays and 9.30 am to $5.30 \mathrm{pm}$ on weekends was selected to control for individual differences in time spent wearing the monitors. The differing timeframes for weekdays and weekends also reflect the well-documented differences that occur in physical activity patterns between these days. ${ }^{19}$ Students with data for at least $70 \%$ of weekday time $\mathrm{e}^{22}$ and $40 \%$ of weekend time were eligible to be included in the analysis, with non-wearing time defined as $\geq 20$ consecutive minutes of 0 counts ${ }^{22,23}$ and this time was not included in the analysis. Up to $20 \%$ of children removed their accelerometer after $3.00 \mathrm{pm}$, when school finished. Students with fewer than three weekdays of complete monitoring data were excluded from the analyses and data from the first day was removed to eliminate participant reactivity to wearing the monitor. For each student, time spent in light, moderate, vigorous and moderate-to-vigorous physical activity were calculated separately using the energy prediction equation developed by Freedson and colleagues: METs $=2.757+(0.0015 \times$ counts per minute $)-(0.08957 \mathrm{x}$ age $(\mathrm{yr}))-$ $(0.000038 \mathrm{x}$ counts per minute $\mathrm{x}$ age $(\mathrm{yr})){ }^{24}$

Data were analysed separately for Aboriginal and Torres Strait Islander and non-indigenous children. All analyses were undertaken using SAS (Version 9.1) and STATA (Version 10) and statistical significance was set at an alpha level of 0.05 . For the validity analyses, only self-reported summer physical activities were used, as this corresponded with the time when accelerometers were worn. Only week day data were included in the final analyses as $50 \%$ of children with sufficient weekday data did not record adequate data on weekends. The level of agreement between weekday self-report MVPA and accelerometer-based MVPA were assessed using Bland
Altman plots ${ }^{25}$ and Pearsons (measuring consistency between the methods) and Intra-class correlation (ICC) (agreement between the methods) coefficients. ${ }^{26}$ The mean weekday MVPA (mins/day) was calculated for both the accelerometer and survey data. Wald tests adjusted for clustering of children within schools were conducted to compare mean weekday MVPA by gender, BMI status and Indigenous status. A regression analysis adjusted for clustering within schools using the $<$ svy $>$ commands in STATA, was performed to compare mean weekday MVPA across age groups.

Age, gender, Indigenous status and BMI were explored as variables associated with MVPA using simple linear regressions. Multiple regression with backwards step-wise elimination were used to arrive at a parsimonious model using the $<$ svy $>$ commands in STATA; and variables were excluded on the basis of highest $p$-values until only those with $p<0.05$ were left in the model. In the regression analyses BMI was included as a continuous variable, and age as categorical (1 year categories). Additionally, the percentage of children meeting the current national physical activity guidelines $^{6}$ (i.e. $\geq 60 \mathrm{mins} /$ day MVPA) on weekdays for both self-report and accelerometer data was reported.

\section{Consultation}

This study is part of the Many Rivers Diabetes Prevention Project, a program of both health promotion activities and research, initiated and directed by the participating Aboriginal communities who are consulted on all strategies and publications.

\section{Results \\ Participants}

All 11 schools approached agreed to participate in the study. The study population was made up of 102 Aboriginal and Torres Strait Islander children (response rate 47\%) and 157 nonIndigenous children (response rate $=28 \%$ ). Of these 259 children, 230 completed the modified APARQ and 154 wore accelerometers (a convienience sample of predominately year 6 students due to the demands of study tasks and availability of the accelermeters). Eighty-six children with a mean age of 11.1 years $(\mathrm{SD} \pm 0.7)$ had sufficient accelerometer data available for validation (41\% boys; $47 \%$ Aboriginal and Torres Strait Islander). Of the 230 who completed the survey, 64 were overweight or obese, and of the 86 with accelerometer data, 20 were overweight or obese.

We present the results in two different study groups; the Accelerometer Group contains accelerometer data and a sub-sample of survey data used for the validation study, and both are also used for descriptive purpose; the MRPARQ Group contains all survey data and is for descriptive purposes only.

\section{Validation}

The correlation between mean weekday MVPA (mins/ day) as measured by the survey and accelerometer, by student characteristics are given in Table 1. Overall, these suggest a weak to modest correspondence between the accelerometer and survey data for the whole sample and for the variables of Indigenous status, age, gender and BMI. The ICCs range between 0.05 and 0.38 (all statistically significant $p<0.05$ ) and Pearson correlations (r) mostly between 0.3 and 0.4 . Correlations increase with age, 
Table 1: Pearson (r) and Intra-class Correlations (ICC) for Average Weekday Daily MVPA Accelerometer and Survey $(n=86)$.

\begin{tabular}{lllll}
\hline & Variables & $\mathbf{n}$ & $\mathbf{r}^{\mathbf{a}}$ & ICC $^{\mathbf{b}}$ \\
\hline All & & 86 & 0.37 & 0.25 \\
Gender & Male & 35 & 0.39 & 0.30 \\
& Female & 51 & 0.36 & 0.20 \\
BMI & Not O'w/obese & 66 & 0.36 & 0.25 \\
& O'w / obese & 20 & $0.40^{\mathrm{a}}$ & 0.25 \\
Indigenous & Aboriginal \& Torres & 40 & $0.31^{\mathrm{a}}$ & 0.16 \\
Status & Strait Islander & & & \\
& non-Indigenous & 46 & 0.38 & 0.31 \\
Age & 10 & 18 & $0.09^{\mathrm{a}}$ & 0.05 \\
& 11 & 53 & 0.37 & 0.27 \\
& 12 & 15 & 0.68 & 0.38
\end{tabular}

\section{Notes:}

a) All Pearson results $<0.05$ except variables Overweight/Obese, Aboriginal and Torres Strait Islander and Age 10.

b) All ICC's are significant $<0.05$.

ranging from 0.05 to 0.38 (ICC) and 0.09 to 0.68 (Pearson) for mean weekday daily MVPA.

The Bland Altman plot (Figure 1) shows the agreement for mean weekday MVPA among Aboriginal and Torres Strait Islander and non-Indigenous children. The survey and accelerometer data agree reasonably closely around the average MVPA range; but the level of disagreement between the two methods increases at either end of the range of mean MVPA, and more so for Aboriginal and Torres Strait Islander children.

When the mean daily weekday MVPA for the survey and accelerometer participants in the Accelerometer Group are plotted on a box and whisker plot there is an indication of some equivalence between the means for the whole sample (Figure 2a). The mean weekday daily MVPA for the survey is 141 minutes $(\mathrm{SD}=85.6)$ and for the accelerometer is 115 minutes $(\mathrm{SD}=37.2)$. However, the scatter plot of these data demonstrates a weak relationship between the measures at an individual level, with a wide variance around the mean noticeable for the survey (refer to Figure $2 b$ ).

\section{Description of physical activity}

\section{Level of MVPA}

The 86 participants in the Accelerometer Group have a mean weekday daily MVPA of 141.1 minutes $(\mathrm{SD}=85.6)$ by survey and 115.2 minutes $(\mathrm{SD}=37.2)$ by accelerometer. In the MRPARQ Group the mean weekday daily MVPA is 156.7. Mean MVPA, confidence intervals and $p$-values for the measures in both groups is provided in Table 2 .

\section{Variables associated with MVPA}

Aboriginal and Torres Strait Islander children on average undertook around 18 minutes more weekday MVPA than nonIndigenous children based on accelerometer data, between 23 and 39 minutes more MVPA according to survey data and around 48 minutes more MVPA when adjusted for BMI in the parsimonious model of the Accelerometer Group survey data, where the difference reaches statistical significance (refer to Table 3).

Weekday MVPA differs significantly by gender in the MRPARQ Group, with boys having on average 32 minutes more MPVA, and in the Accelerometer Group for the accelerometer data only with boys having 29 minutes more MVPA (refer to Table 3). Weekday MVPA also varies significantly with age for the accelerometer data but not in either set of survey data. In the parsimonious model (Table 3), 12-year-olds undertake about 14 to 25 minutes less MVPA on average than either 11 or 10-year-olds, respectively (refer to Table 3). This same model shows some evidence of a relationship between BMI and MVPA in the Accelerometer Group, reaching statistical significance in the survey sub-group only, with MVPA decreasing by about 3.1 minutes for every one unit increase in BMI.
Figure 1: Bland Altman plot of mean weekday MVPA for Aboriginal and Torres Strait Islander $(\mathrm{n}=40)$ and non-Indigenous children $(n=46)$.

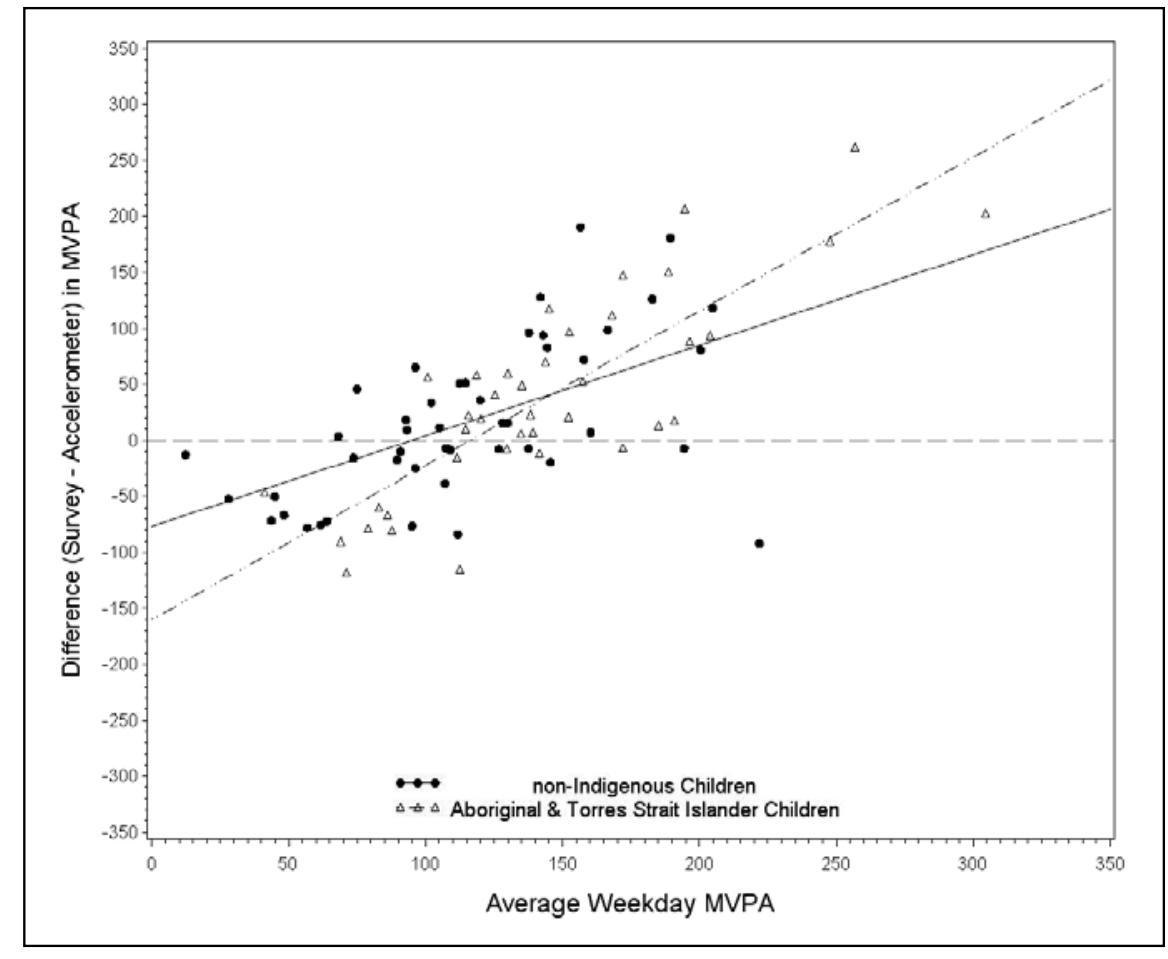


Figure 2a: Box and whisker plot of mean weekday MVPA for survey and accelerometer (Accelerometer Group).

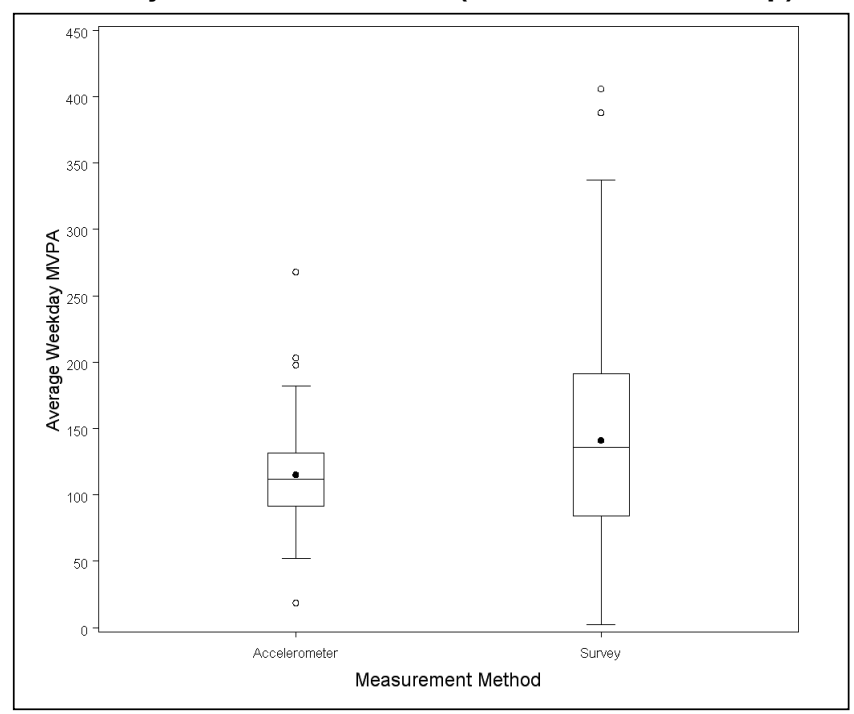

Prevalence and type of $\geq 60$ mins/day of MVPA on weekdays

A total of $97 \%$ of children who wore the accelerometer and $83 \%$ of those who completed the survey accumulated a minimum of $60 \mathrm{mins} /$ day of MVPA on their average weekday (refer to Table 4), and for Aboriginal and Torres Strait Islander children this was $100 \%$ and $81 \%$, respectively. Participants accumulated most of their weekday MVPA in the context of non-organised activity (around $86 \%$ as measured by the survey), and during school hours (around $73 \%$ as measured by the accelerometer).

\section{Discussion}

The two aims of this study were to determine the validity of a self-report measure of physical activity among Aboriginal and Torres Strait Islander and non-Indigenous rural primary school children, and to describe the physical activity of these children.
Figure 2b: Scatterplot of mean weekday MVPA for survey and accelerometer (Accelerometer Group).

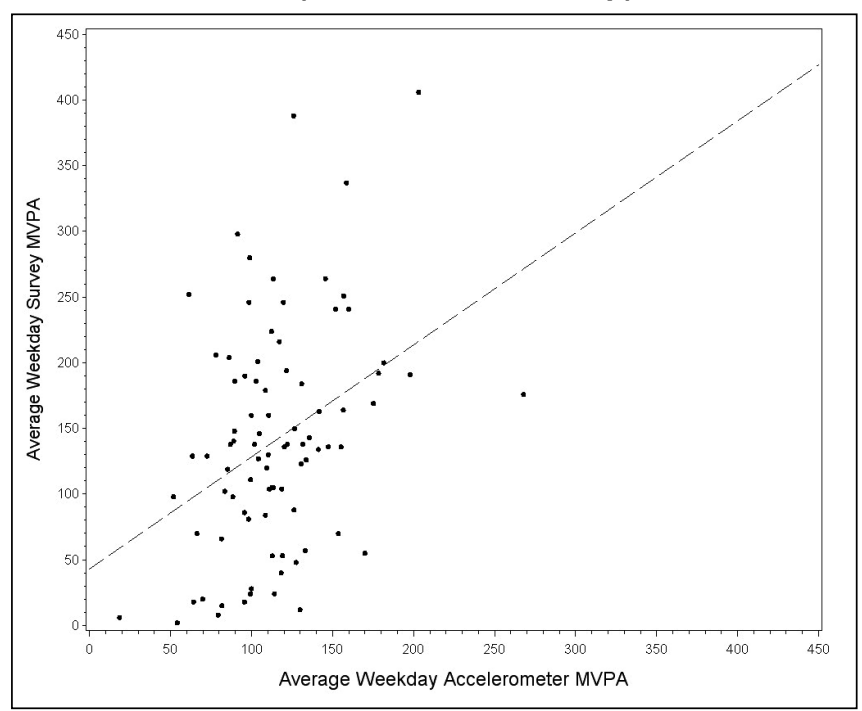

We discuss the levels of, variables associated with, and types of physical activity, as well as the percentage of children with $\geq 60$ mins/day of MVPA. We found that the MRPARQ shows weak to modest validity relative to the accelerometer on weekdays for both Aboriginal and Torres Strait Islander and non-Indigenous children alike, and that Aboriginal and Torres Strait Islander children regardless of gender tend to be more active than nonIndigenous children.

\section{Validation}

The strength of correspondence between the measures obtained in this study for weekdays are similar to previous physical activity self-report validation studies with children and adolescents ${ }^{2,27-32}$ with the ICCs lower than the Pearson correlation coefficients demonstrating generally poor agreement and modest correlation. The Pearsons correlation is similar in magnitude to results from

Table 2: Mean weekday MVPA (mins/day; 95\% confidence intervals) by gender, BMI, Indigenous status and age.

\begin{tabular}{|c|c|c|c|c|c|c|c|c|}
\hline \multirow[t]{2}{*}{ Variable } & \multirow[b]{2}{*}{$\mathbf{n}$} & \multicolumn{4}{|c|}{ Accelerometer Group $(n=86)$} & \multicolumn{3}{|c|}{$\begin{array}{c}\text { MRPARQ Group }(n=230) \\
\text { Survey }\end{array}$} \\
\hline & & $\begin{array}{l}\text { Mean MVPA } \\
(95 \% \mathrm{Cl})\end{array}$ & p-value ${ }^{a}$ & $\begin{array}{l}\text { Mean MVPA } \\
(95 \% \mathrm{Cl})\end{array}$ & $p$-value ${ }^{a}$ & $\mathbf{n}$ & $\begin{array}{l}\text { Mean MVPA } \\
(95 \% \mathrm{Cl})\end{array}$ & $p$-value ${ }^{a}$ \\
\hline$\overline{\text { All }}$ & 86 & $141.1(113.9-168.4)$ & & $115.2(108.0-122.5)$ & & 230 & $156.7(138.3-175.5)$ & \\
\hline \multicolumn{9}{|l|}{ Gender } \\
\hline Boys & 35 & $147.6(98.8-196.4)$ & 0.60 & $132.0(120.7-143.3)$ & 0.004 & 99 & $175.6(150.3-200.9)$ & 0.003 \\
\hline Girls & 51 & $136.7(113.4-160.0)$ & & $103.7(93.8-113.6)$ & & 131 & $143.2(125.0-161.5)$ & \\
\hline \multicolumn{9}{|l|}{$\mathrm{BMI}^{\mathrm{b}}$} \\
\hline Not O'w/obese & 66 & $143.7(110.3-177.1)$ & 0.62 & $118.1(108.8-127.4)$ & 0.15 & 164 & $152.5(136.9-168.1)$ & 0.30 \\
\hline O’w/obese & 20 & $132.6(95.9-169.3)$ & & $105.6(92.9-118.4)$ & & 64 & $168.7(130.8-206.6)$ & \\
\hline \multicolumn{9}{|l|}{ Indigenous Status } \\
\hline $\begin{array}{l}\text { Aboriginal and Torres } \\
\text { Strait Islander }\end{array}$ & 40 & $161.8(114.2-209.4)$ & 0.09 & $124.6(113.5-135.8)$ & 0.06 & 84 & $171.8(133.9-209.8)$ & 0.18 \\
\hline Non-Indigenous & 46 & $123.1(103.3-143.0)$ & & $107.0(96.1-117.9)$ & & 146 & $148.5(133.8-163.3)$ & \\
\hline \multicolumn{9}{|l|}{ Age $^{\mathrm{b}}$} \\
\hline 10 & 18 & $149.2(119.2-179.2)$ & 0.50 & $123.3(109.0-137.5)$ & 0.018 & 38 & $151.5(129.4-173.6)$ & 0.96 \\
\hline 11 & 53 & $138.9(109.3-168.6)$ & & $116.9(110.2-123.7)$ & & 119 & $161.1(126.3-195.8)$ & \\
\hline 12 & 15 & $139.2(110.7-167.7)$ & & $99.4(80.2-118.7)$ & & 71 & $153.3(127.1-179.6)$ & \\
\hline
\end{tabular}

Notes:

a) $p$-value for Wald test adjusted for clustering.

b) MRPARQ group - two ID's with no BMI or Age assigned and not included in relevant analysis. 
the only other physical activity study that included Australian Indigenous ( $\mathrm{n}=63)$ and non-Indigenous adolescents $(\mathrm{n}=59),{ }^{14}$ which showed statistically significant $(p=<0.05)$ Spearmans correlation coefficients ( 0.32 to 0.34 ), although there are differences between the studies regarding the recall timeframe (24-hour recall), the calculation of MVPA (30-minute blocks) and the criterion measures (electronic pedometers).

The Bland Altman plots shows similar association between the methods for both Aboriginal and Torres Strait Islander and non-Indigenous children. At either end of the range of activity (i.e. low activity or high activity levels) the disagreement between the measures increases, with the survey over-estimating activity levels for very active children and under-estimating for children with low activity levels. This reflects the well-documented limitations of young people to accurately self-report, ${ }^{2,28,33,34}$ and their tendancy to over and/or under report as described in other studies. ${ }^{29,35}$

Aboriginal and Torres Strait Islander community members report that children may be wary of non-Indigenous authority figures and their intentions regarding the use of the survey information (i.e. negative use by 'Government'), and that children's response to this is a heightened awareness of the need to give a 'good' impression, and to hide what they perceive to be problematic information. However, the similar levels of correspondence between the measures that this study found indicate that Aboriginal and Torres Strait Islander provide results that are as valid as nonIndigenous children given appropriate cultural support.

A difference is noted with the ICCs for gender reflecting the known differences in activity levels and type between genders. ${ }^{8,13,31}$ Both the Pearson and ICC coefficients increase with age in this study reflecting the known improvement in children's recall accuracy that occurs with age. ${ }^{36}$

A number of issues may have influenced weekday agreement in this study. Each method of measurement captures slightly different types of physical activity. The survey does not capture 'incidental' activity or very short bursts of MVPA, a behaviour reported in young children ${ }^{11}$ and participants are likely to record the amount of time that they are in the activity setting, and not the time they are actually active,${ }^{10}$ biasing the results towards an increase amount
Table 4: Percentage (\%) of children with $\geq 60 \mathrm{~min} \cdot \mathrm{d}^{-1}$ of MVPA - weekday only.

\begin{tabular}{llrrrr}
\hline Variable & & \multicolumn{2}{c}{$\begin{array}{c}\text { MRPARQ } \\
\text { Group }\end{array}$} & \multicolumn{2}{c}{ A'meter } \\
& & Group \\
n & $\%$ & n & $\%$ \\
\hline All & & 230 & 83 & 86 & 97 \\
Gender & Boys & 99 & 87 & 35 & 100 \\
& Girls & 131 & 80 & 51 & 94 \\
BMI $^{\text {a }}$ & Not O'w/obese & 164 & 84 & 66 & 95 \\
& O'w/obese & 64 & 80 & 20 & 100 \\
Indigenous & Aboriginal and Torres & 84 & 81 & 40 & 100 \\
Status & Strait Islander & & & & \\
& non-Indigenous & 146 & 84 & 46 & 93 \\
Age $^{\text {a }}$ & 10 & 38 & 79 & 18 & 100 \\
& 11 & 119 & 83 & 53 & 96 \\
& 12 & 71 & 85 & 15 & 93 \\
\hline
\end{tabular}

Notes:

a) MRPARQ Group - two ID'S with no BMI or Age assigned and not included in relevant calculations.

of activity. The accelerometer addresses these limitations but, conversely, has other drawbacks: up to $20 \%$ of children removed the device after school and this is probably related to the type of after school activity they were engaged in (e.g. water-based activity after school in these summer months); discomfort when wearing the device in the summer heat; or perceiving the device to be socially undesirable.

The mean weekday daily MVPA obtained by survey and by accelerometer has some equivalence, despite the wide variance of the survey data, which may be due to the survey capturing more after school activity than the accelerometer (with a range of activities undertaken by children at this time), and to younger children's difficulty in estimating duration and frequency of activity on the self-report measure.

\section{Description of physical activity}

\section{The level of MVPA}

The children in this study had a mean weekday daily MVPA of about 150 minutes by survey and 115 minutes by accelerometer and these results are commensurate with key International studies. ${ }^{1,31,37}$

Table 3: Variables associated with mean weekday MVPA in both the Accelerometer and MRPARQ Groups.

\begin{tabular}{|c|c|c|c|c|c|c|c|c|c|c|}
\hline \multirow{3}{*}{\multicolumn{2}{|c|}{ Variable }} & \multicolumn{6}{|c|}{ Accelerometer Group $(n=86)$} & \multirow{2}{*}{\multicolumn{3}{|c|}{$\begin{array}{l}\text { MRPARQ Group }(n=230) \\
\text { Survey }\end{array}$}} \\
\hline & & \multicolumn{3}{|c|}{ Survey } & \multicolumn{3}{|c|}{ Accelerometer } & & & \\
\hline & & Coeff & $p$-value ${ }^{a}$ & $\mathbf{R}^{2}$ & Coeff & $p$-value ${ }^{a}$ & $\overline{\mathbf{R}^{2}}$ & Coeff & $p$-value ${ }^{\text {a }}$ & $\mathbf{R}^{2}$ \\
\hline \multicolumn{11}{|c|}{ SIMPLE LINEAR REGRESSION MODEL } \\
\hline \multicolumn{2}{|c|}{ Gender ${ }^{b}$} & -10.92 & 0.60 & 0.004 & -28.29 & 0.004 & 0.15 & -32.40 & 0.003 & 0.03 \\
\hline \multicolumn{2}{|l|}{ BMI } & -2.52 & 0.09 & 0.02 & -1.53 & 0.06 & 0.03 & 0.66 & 0.64 & 0.0007 \\
\hline \multicolumn{2}{|c|}{ Indigenous Status ${ }^{c}$} & 38.66 & 0.09 & 0.05 & 17.63 & 0.06 & 0.06 & 23.29 & 0.18 & 0.01 \\
\hline \multirow[t]{2}{*}{ Age } & 10 & 10.01 & 0.48 & 0.002 & 23.85 & 0.03 & 0.04 & -1.84 & 0.91 & 0.002 \\
\hline & 11 & -0.32 & 0.98 & & 17.52 & 0.04 & & 7.70 & 0.73 & \\
\hline \multicolumn{11}{|c|}{ BACKWARDS STEPWISE REGRESSION MODEL } \\
\hline \multicolumn{4}{|c|}{ Gender $^{\mathrm{b}}$} & & -26.91 & 0.004 & & -32.82 & 0.003 & \\
\hline \multicolumn{2}{|l|}{ BMI } & -3.11 & 0.03 & & & & & & & \\
\hline \multicolumn{2}{|c|}{ Indigenous Status ${ }^{c}$} & 47.53 & 0.02 & 0.09 & & & 0.19 & & & 0.04 \\
\hline \multirow[t]{2}{*}{ Age } & 10 & & & & 25.45 & 0.003 & & & & \\
\hline & 11 & & & & 13.52 & 0.02 & & & & \\
\hline
\end{tabular}

Notes: $\quad$ a) p-value adjusted for clustering.

b) Boys are the referent group.

c) Non-Indigenous children are the referent group. 
However, our accelerometer results show somewhat lower mean MVPA when compared with other national studies, with between 12 and 17 minutes less mean MVPA. ${ }^{38,39}$ This may be due to some of the school-aged children removing the accelerometer after school, or sampling bias.

\section{Variables associated with MVPA}

\section{Aboriginal and Torres Strait Islander children}

This study found that Australian Aboriginal and Torres Strait Islander children tend to be more active than non-Indigenous children, that this is consistent across both the Accelerometer and MRPARQ Groups, and that this is in accord with the only other physical activity study with this population. ${ }^{14}$ In our study this difference reaches statistical significance in one model only, which may be due to clustering and the small sample size. The difference in the ICCs between Aboriginal and Torres Strait Islander and nonIndigenous children may also reflect differing levels of physical activity. As already noted, we found that disagreement between the measures increases for very active children, and if Aboriginal and Torres Strait Islander children are more active then the agreement (as seen by the ICC values) between the accelerometer and survey data will be less than for non-Indigenous children, as seen in our results. The Pearsons correlation will, however, not be influenced by these differences if they are consistent.

Feedback from Aboriginal and Torres Strait Islander Health workers who were part of the project and community focus groups conducted as part of the broader program of research, ${ }^{40}$ state that there are a number of possible reasons for this higher activity. In Australian Aboriginal and Torres Strait Islander communities 'family' includes the extended family and a higher proportion of Aboriginal and Torres Strait Islander people are under 15 years of age $(37 \%)$ compared with non-Indigenous people (19\%). ${ }^{4}$ As a consequence, there may be more children in the family unit to play with and play is encouraged, ${ }^{40}$ and in the rural setting of this study this may provide children with more area for play. Largely due to lesser financial means, ${ }^{4,40}$ Aboriginal and Torres Strait Islander children may "stay at home and make their own fun", participate less in organised sport, and may be less likely to have screen-based games, a known impediment to activity in children. In this study, a number of Aboriginal and Torres Strait Islander communities are located out of town, private transport can be unavailable and public transport is very limited ( 13 of 18 community focus groups $s^{40}$ identified transport as a major concern), and many children walk for transport each day, sometimes substantial distances. ${ }^{40}$ Further qualitative work needs to be done to more closely examine these possible determinants.

\section{Other variables associated with MVPA}

In this study gender is strongly associated with mean weekday MVPA and this relationship reflects that observed in many studies. ${ }^{7,8,13,31}$ Internationally, numerous studies note that boys tend to have higher physical activity levels than girls, with activity levels for both boys and girls declining as they reach adolescence. . $^{10,13,41-43}$ Similarly, in the accelerometer data we found evidence of declining physical activity with increasing age. The mean MVPA for gender in a US study of children of the same age as this study ranged from around 130 to 160 minutes per day for boys and 95 to 130 minutes for girls. ${ }^{42}$ This study, however, argued that these gender differences disappear when physical maturity is taken into account.

In our study there is some evidence of an association between decreasing physical activity and increasing BMI. This finding is supported by other studies that examine this association ${ }^{2,43}$ and indicates the importance of physical activity as a strategy for reducing overweight and obesity.

\section{Prevalence of $\geq 60$ mins/day of MVPA on weekdays}

Our findings (Table 4) support the conclusions reached in a recent review of the physical activity of children, ${ }^{44}$ that internationally most children between the ages of 10 and 13 years accumulate $\geq 60 \mathrm{mins} /$ day of MVPA day as measured by an objective measure, and this is supported by a number of other studies. ${ }^{8,10,11,44}$ Nationally, studies of young people of similar age using the same measures has found that the prevalence of $\geq 60 \mathrm{mins} /$ day of MVPA over a whole week is commensurate with our weekday study results. ${ }^{12,39}$

The results for Aboriginal and Torres Strait Islander children in our study are comparable with their non-Indigenous counterparts, though marginally lower for self-report when compared with the other study with the Indigenous youth where $92 \%$ accumulated a minimum of $60 \mathrm{mins} /$ day of MVPA as measured by a 24-hour recall, ${ }^{14}$ and higher than the results achieved by children on the same measure in another study. ${ }^{45}$

\section{Types of physical activity}

The survey group data shows that organised activity contributes only around $14 \%$ of the average weekday daily MVPA of participants. This does not vary widely across the variables with organised activity contributing $11 \%$ to total MVPA for Aboriginal and Torres Strait Islander children and $15 \%$ for non-Indigenous children. Few studies have examined the contribution of the type of activity to daily physical activity, with one finding that youth sport contributed $23 \%$ of total daily MVPA as measured by accelerometer. ${ }^{46}$ However, an Australian study ${ }^{45}$ using the APARQ has shown that of children with a mean age of 13.3 years, boys spend a median per day of $41 \%$ of MVPA time in organised activity in summer and girls 52\%. Reasons for the difference between studies include the younger age of children in our study (two years), and it is recognised that there is a change in the type of activity as children reach adolescence with amount of time in non-organised activity decreasing. ${ }^{7}$ Our population was entirely rural and barriers to participating in organised sport, including distance, transport, cost and availability, are magnified. ${ }^{40}$ Finally, our study did not include weekend data, a time when organised activity can be undertaken.

The accelerometer data shows that activity undertaken during school hours is the main contributor (at 73\%) to average daily weekday MVPA, and this is consistent with previous studies in indicating that a large component of MVPA, between $50 \%$ to $70 \%$, is accumulated during school time. ${ }^{47,48}$ 


\section{Generalisability and limitations}

There are several possible biases in this study. The main issue is selection bias, with relatively low participation rates, and differential participation rates; $47 \%$ for Aboriginal and Torres Strait Islander children and $28 \%$ for non-Indigenous children. We also made no comparison with non-participants. However, we anticipate a bias to the null given that the recruitment process for non-Indigenous children did not include any follow-up (recruiting the more motivated and possibly more active children), so the differences by Indigenous status that we found are likely to be an underestimate. The second potential bias is the possibility of a differential Hawthorne effect, with Aboriginal and Torres Strait Islander children potentially overreporting due to involvement of the local Aboriginal and Torres Strait Islander communities and AHWs. However, this bias would have affected self-report only and the fact that the accelerometer results were similar makes this possibility less likely. Additionally, the involvement of the Aboriginal and Torres Strait Islander community may simply have addressed a pre-existing inequity where Aboriginal and Torres Strait Islander children, due to a lack of appropriate cultural support, under-perform on tasks devised and supervised by the dominent culture. Our sample of predominately year 6 students in the Accelerometer study could bias results towards an improved recall with these older students and possibly a closer correspondence between the methods than if predominately year 5 students were sampled. The loss of accelerometer data from up to $20 \%$ of the children after school hours led to an under-enumeration of non-school weekday MVPA, and the possibility that results in this study are an underestimate of the true values. Accelerometer data loss on weekends resulted in the inability of the study to examine validity of the MRPARQ on weekends, and in future studies provision of participant support on weekends in addition to the weekdays may address this issue. While we were able to make a same season (summer) comparions of measures, the results may not be generalisable to the winter months, in addition the fact that accelerometery data was only collected over one week may mean that it is not representative of a 'usual week'. The age range of participants may also limit generalisability of results.

\section{Conclusion and implications}

Given culturally appropriate support, Aboriginal and Torres Strait Islander children provide self-report data that is at least as valid as non-Indigenous children. Researchers need to be aware that activity levels may differ between variables as Aboriginal and Torres Strait Islander children regardless of gender tend to be more active than nonIndigenous children. The consistency of this result within our study and when compared to the only other study with Indigenous youth requires further investigation and should also examine the nature of physical activity in this population.

The finding of higher activity levels for Aboriginal and Torres Strait Islander children suggests a key intervention point for health promotion activities; the need to maintain the high levels of activity shown by Aboriginal and Torres Strait Islander children of either gender, into adolescence and adulthood. ${ }^{49}$ This could be achieved by maximising opportunities for physical activity at school and in a non-organised form at any time of day; and examining ways in which after school activities and organised activity can be made more readily available. To do this successfully, barriers to participation (particularly cost and transport) in physical activity must be addressed in rural communities, and cultural issues around physical activity should be further explored and addressed in Australia's Aboriginal and Torres Strait Islander children.

\section{Acknowledgements}

The authors would like to acknowledge the participating Aboriginal communities. This study was undertaken with the support and guidance of the following Many Rivers Diabetes Prevention Project team members: Laurie J. Clay and Stephen V. Blunden (Durri Aboriginal Medical Service Corporation Kempsey), Robin Roberts (Biripi Aboriginal Medical Service Taree), Darren Barton (Awabakal Aboriginal Medical Service Newcastle) and Associate Professor Michael Booth (University of Sydney)

The authors declare that they have no competing interests. This study was supported by grants from the following bodies: Telstra Foundation; Diabetes Australia; Eli Lilly; Commonwealth Department of Health and Ageing; and the NSW Aboriginal Health Promotion Community grants scheme.

\section{References}

1. Nader PR, Bradley CB, Houts RM, McRitchie SL, O'Brien M. Moderate-toVigorous Physical Activity From Ages 9 to 15 Years. JAMA. 2008;300(3):295305.

2. Trost S. Development of Recommendations for Children's and Youths Participation in Health Promoting Physical Activity [discussion paper]. Canberra (AUST): Department of Health and Aging; 2005.

3. Flynn MA, McNeil DA, Maloff B, Mutasingwa M, Wu M, Ford D, et al. Reducing obesity and related chronic disease risk in children and youth: a synthesis of evidence with 'best practice' recommendations. Obes Rev. 2006;7 Suppl 1:7-66.

4. Australian Institute of Health and Welfare. The Health and Welfare of Australia's Aboriginal and Torres Strait Islander Peoples 2008. Canberra (AUST): ABS; 2008. Catalogue No.: 4704.0

5. Australian Institute of Health and Welfare. Diabetes: Australian Facts 2008 Canberra (AUST): AIHW; 2008. Report No.: CVD 40.

6. Department of Health and Aging [homepage on the Internet]. Canberra (AUST): Commonwealth of Australia; 2005 [cited 2008 Sept 17]. Physical Activity-Australia's Physical Activity Recommendations for 5 - 12 Year olds. Available from: http://www.health.gov.au/internet/main/publishing.nsf/Content health-pubhlth-strateg-phys-act-guidelines\#rec_5_12

7. Strong WB, Malina RM, Blimkie CJ, Daniels SR, Dishman RK, Gutin B, et al. Evidence based physical activity for school-age youth. J Pediatr. 2005;146(6):732-7.

8. Sleap M, Tolfrey K. Do 9- to 12 yr-old children meet existing physical activity recommendations for health? Med Sci Sports Exerc. 2001;33(4):591-6.

9. World Health Organisation. Recommended Amount of Physical Activity. In: Global Strategy on Diet, Physical Activity and Health [fact sheet on the Internet]. Geneva (CHE): WHO; 2008 [cited 2008 July 17]. Available from: http://www.who.int/dietphysicalactivity/factsheet_recommendations/en/index. html

10. Pate RR, Freedson P, Sallis JF, Taylor WC, Sirard J, Trost S, et al. Compliance with Physical Activity Guidelines: Prevalence in a Population of Children and Youth. Ann Epidemiol. 2002;12(5):303-8.

11. Riddoch CJ, Bo Andersen L, Wedderkopp N, Harro M, Klasson-Heggebo L, Sardinha LB, et al. Physical activity levels and patterns of 9- and 15-yr-old European children. Med Sci Sports Exerc. 2004;36(1):86-92.

12. Hardy LL, Okely AD, Dobbins T, Booth ML. Physical activity among adolescents in New South Wales (Australia):1997 and 2004. Med Sci Sports Exerc. 2008;40(5):835-41.

13. Van Der Horst K, Paw MJ, Twisk JW, Van Mechelen W. A brief review on correlates of physical activity and sedentariness in youth. Med Sci Sports Exerc. 2007;39(8):1241-50 
14. Trost S, Marshall AL, Miller R, Hurley J, Hunt J. Validation of a 24-h physical activity recall in indigenous and non-indigenous Australian adolescents. $J \mathrm{Sci}$ Med Sport. 2007;10(6):428-35.

15. Zubrick S, Lawrence D, Silburn S, Blair E, Milroy H, Wilkes T, et al. The Western Australian Aboriginal Child Health Survey: The Health of Aboriginal Children and Young People. Perth (AUST): Telethon Institute for Child Health Research; 2004.

16. Booth M, Oakley A. The validity and reliability of the Adolescent Physical Activity Recall Questionnaire. Med Sci Sports Exerc. 2002;34:1986-95.

17. Cole TJ, Bellizzi MC, Flegal KM, Dietz WH. Establishing a standard definition for child overweight and obesity worldwide: International survey. $B M J$. 2000;320(7244):1240-3.

18. Troiano RP, Berrigan D, Dodd KW, Masse LC, Tilert T, McDowell M. Physical Activity in the United States Measured by Accelerometer. Med Sci Sports Exerc. 2007;40(1):181-8.

19. Rowlands A. Accelerometer Assessment of Physical Activity in Children: An Update. Pediatr Exerc Sci. 2007;19(3):252-67.

20. Mattocks C, Ness A, Leary S, Tilling K, Blair E, Shield J, et al. Use of Accelerometers in a large field-based study of children: protocols, design issues, and effects on precision. $J$ Phys Act Health. 2008;5(Supp 1):S94-S107.

21. Ainsworth BE, Haskell WL, Whitt MC, Irwin ML, Swartz AM, Strath SJ, et al. Compendium of physical activities: an update of activity codes and MET intensities. Med Sci Sports Exerc. 2000;32 Suppl 9:498-516.

22. Masse LC, Fuemmeler BF, Anderson CB, Matthews CE, Trost SG, Catellier DJ, et al. Accelerometer data reduction: a comparison of four reduction algorithms on select outcome variables. Med Sci Sports Exerc. 2006;37 Suppl 11:544-54.

23. Alhasssan S, Sirard JR, Spencer TR, Varady A, Robinson TN. Estimating physical activity from incomplete accelerometer data in field studies. $J$ Phys Act Health. 2008;5 Suppl 1:112-25.

24. Freedson P, Pober D, Janz KF. Calibration of accelerometer output for children. Med Sci Sports Exerc. 2005;37 Suppl 11:523-30.

25. Bland JM, Altman DG. Measuring agreement in method comparison studies. Stat Methods Med Res. 1999;8(2):135-60.

26. Morton PA, Dobson AJ. Assessing Agreement. Med J Aust. 1989;150:384-7.

27. Kohl HW, Fulton JE, Caspersen CJ. Assessment of Physical Activity among Children and Adolescents: A Review and Synthesis. Prev Med. 2000;31(2):S54-S76

28. Sirard JR, Pate RR. Physical activity assessment in children and adolescents. Sports Med. 2001;31(6):439-54.

29. Troped PJ, Wiecha JL, Fragala MS, Matthews CE, Finkelstein DM, Kim J, et al. Reliability and Validity of YRBS Physcial Activity Items among Middle School Students. Med Sci Sports Exerc. 2007:416-25.

30. Sallis JF. Self-report measures of children's physical activity. $J$ Sch Health. 1991;61(5):215-9.

31. Trost SG, Pate RR, Sallis JF, Freedson PS, Taylor WC, Dowda M, et al. Age and gender differences in objectively measured physical activity in youth. Med Sci Sports Exerc. 2002;34(2):350-5.

32. Telford A, Salmon J, Jolley D, Crawford D. Reliability and Validity of Physical Activity Questionnaires for Children: The Children's Leisure Activities Study Survey (CLASS). Pediatr Exerc Sci. 2004;16(1):64-78.
33. Welk GJ, Corbin CB, Dale D. Measurement issues in the assessment of physical activity in children. Res Q Exerc Sport. 2000;71(2):59-73.

34. Sallis JF, Saelens BE. Assessment of Physical Activity by Self-Report: Status, Limitations, and Future Directions. Res Q Exerc Sport. 2000;71(2):1.

35. Wong SL, Leatherdale ST, Manske SR. Reliability and validity of a school-based physical activity questionnaire. Med Sci Sports Exerc. 2006;38(9):1593-600.

36. Trost SG, Pate RR, Ward DS, Saunders R, Riner W. Correlates of objectively measured physical activity in preadolescent youth. Am J Prev Med. 1999; 17(2):120-6.

37. Andersen LB, Harro M, Sardinha LB, Froberg K, Ekelund U, Brage S, et al. Physical activity and clustered cardiovascular risk in children: a cross-sectional study (The European Youth Heart Study). Lancet. 2006;368(9532):299-304.

38. Hesketh K, Crawford D, Salmon J. Children's television viewing and objectively measured physical activity: associations with family circumstance. International Journal of Behavioural Nutrition and Physical Activity. 2006;3(1):36.

39. Telford A, Salmon J, Timperio A, Crawford D. Quantifying and Characterizing Physical Activity AMong 5- to 6- and 10- to 12-Year-Old Children: The Children's Leisure Activities Study (CLASS). Pediatr Exerc Sci. 2005;17: 266-80.

40. Cochrane S. Community Focus Groups on Food and Physical activity availability and issues in rural NSW communities: Many Rivers Diabetes Prevention Project. CRIAH Aboriginal Health Conference. Presentation. Sydney. Australia: Sax Institute, 2008.

41. Hohepa M, Schofield G, Kolt GS, Scragg R, Garrett N. Pedometer-determined physical activity levels of adolescents: differences by age, sex, time of week, and transportation mode to school. J Phys Act Health. 2008;5 Suppl 1:140-52.

42. Sherar LB, Esliger DW, Baxter-Jones AD, Tremblay MS. Age and gender differences in youth physical activity: does physical maturity matter? Med Sci Sports Exerc. 2007;39(5):830-5.

43. Stevens J, Murray DM, Baggett CD, Elder JP, Lohman TG, Lytle LA, et al. Objectively assessed associations between physical activity and body composition in middle-school girls: the Trial of Activity for Adolescent Girls. Am J Epidemiol. 2007;166(11):1298-305.

44. Salmon J, Timperio A. Prevalence, trends and environmental influences on child and youth physical activity. Med Sports Sci. 2007;50:183-99.

45. Okely AD, Booth ML, Hardy L, Dobbins T, Denny-Wilson E. Changes in physical activity participation from 1985 to 2004 in a statewide survey of Australian adolescents. Arch Pediatr Adolesc Med. 2008;162(2):176-80.

46. Wickel EE, Eisenmann JC. Contribution of youth sport to total daily physical activity among 6- to 12-yr-old boys. Med Sci Sports Exerc. 2007;39(9): 1493-500.

47. Mota J, Silva P, Aires L, Santos MP, Oliveira J, Ribeiro JC. Differences in school-day patterns of daily physical activity in girls according to level of physical activity. J Phys Act Health. 2008;5 Suppl 1:90-7.

48. Tudor-Locke C, Lee SM, Morgan CF, Beighle A, Pangrazi RP. Children's pedometer-determined physical activity during the segmented school day. Med Sci Sports Exerc. 2006;38(10):1732-8.

49. Fogelholm M. How physical activity can work? Int J Pediatr Obes. 2008;3 Suppl 1:10-4. 